\title{
Observatório
}

ISSN n² 2447-4266

Vol. 4, n. 4, Jul-Set. 2018

DOI: https://doi.org/10.20873/uft.2447-4266.2018v4n4p27

\section{JOGOS DIGITAIS, APLICATIVOS, SIMULADORES, GAMIFICAÇÃO E NOTICIABILIDADE}

\author{
"Video game is safe for most players \\ and can be useful in health care." \\ Mark Griffiths, professor of gambing Studies
}

A Revista Observatório apresenta seu quarto número de 2018, com capa produzida pela colega, professora e artista Amanda Leite, trazendo dois and dossiês especiais! O primeiro, intitulado JOGOS DIGITAIS, APLICATIVOS, SIMULADORES E GAMIFICAÇÃO - DELINEANDO PRÁTICAS PARA EDUCAÇÃO E SAÚDE, foi organizado pelos colegas Dra. Lynn Alves e Dra. Isa Neves, ambas da Universidade Federal da Bahia (UFBA) e tem o objetivo de socializar as pesquisas que vem sendo realizadas nos programas de Pós-Graduação Stricto Sensu, no Brasil e em Portugal. O segundo, intitulado NOTICIABILIDADE, foi organizado pelos colegas Dra. Lia Seixas, da Universidade Federal da Bahia (UFBA) e Dr. Alfredo Vizeu, da Universidade Federal de Pernambuco (UFPE), e mapea as diferentes acepções que a noticiabilidade adquire nos meios acadêmicos brasileiro e anglo-saxão, além de apontar pistas para se problematizar as modalidades de leitura e formulação nativa do conceito.

Iniciando o pensar sobre JOGOS DIGITAIS, APLICATIVOS, SIMULADORES E GAMIFICAÇÃO - DELINEANDO PRÁTICAS PARA EDUCAÇÃO E SAÚDE, é importante retormarmos a discussão sobre a contribuição dos jogos digitais, simuladores e 


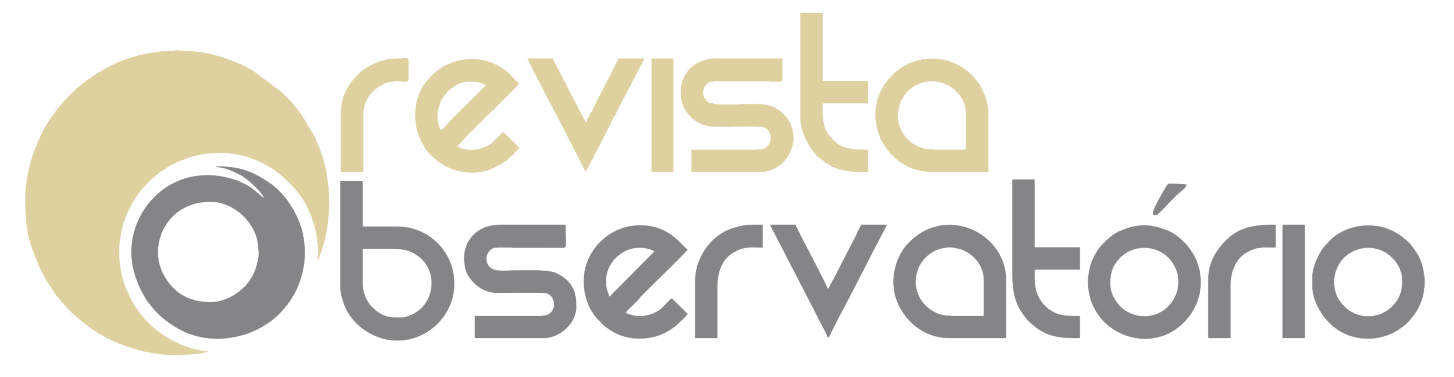

ISSN n² 2447-4266

Vol. 4, n. 4, Jul-Set. 2018

DOI: https://doi.org/10.20873/uft.2447-4266.2018v4n4p27

aplicativos para processos de aprendizagem. Essas discussões vêm crescendo de forma significativa no cenário nacional e internacional, apontando indicativos de que esta mediação pode promover o desenvolvimento de habilidades cognitivas, sociais, afetivas, motoras, dentre outras, em diferentes áreas, especialmente na educação e saúde. Este crescimento pode ser constatado através dos relatórios oficiais financiados pelo Banco Nacional de Desenvolvimento Econômico e Social - BNDES (2014) que apontam também o crescimento das vendas e popularização dos smartphones contribuindo para a produção de jogos, simuladores e aplicativos gamificados incluindo tanto para jogadores com mais experiência, como para jogadores iniciantes, inclusive mulheres (FLEURY; NAKANO; CORDEIRO, 2014).

O relatório também indica que 91,6\% dos jogos produzidos no Brasil em 2013 eram voltados para educação. O desenvolvimento de jogos voltados para saúde ainda é tímido, mas aponta um crescimento (FLEURY; NAKANO; CORDEIRO, 2014; MELLO e ZENDRON, 2015).

Assim, compreendendo que os jogos digitais, os simuladores, os aplicativos e que as práticas gamificadas (que diferem-se da mediação direta dos jogos, mas consistem na utilização da sua lógica) podem se constituir em espaços de aprendizagem para diferentes campos de conhecimento de forma lúdica e divertida; e considerando que o desenvolvimento destes artefatos exige cada vez mais, expertises distintas e processos de formação inicial e permanente para a ocupação de novos campos de atuação, organizamos o Dossiê Jogos digitais, aplicativos, simuladores e gamificação - delineando práticas para educação e saúde que objetiva socializar as pesquisas que vem sendo realizadas nos programas de Pós-Graduação Stricto Sensu, no Brasil e em Portugal. O referido Dossiê está sintonizado com as orientações que norteiam as publicações da Revista Observatório.

O Dossiê está dividido em duas partes. Na primeira denominada JOGOS, APLICATIVOS, SIMULADORES: processos de desenvolvimento e formação, 


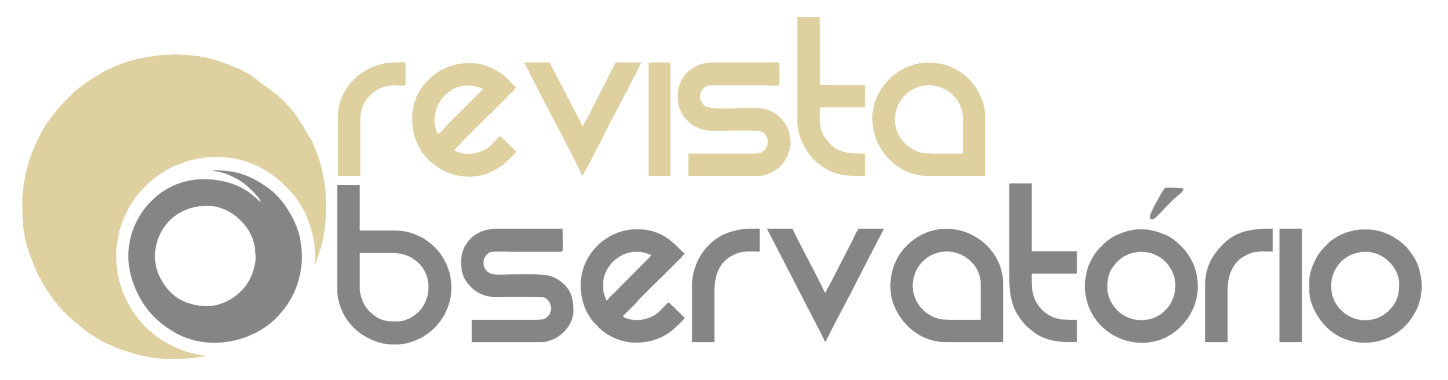

ISSN n² 2447-4266

Vol. 4, n. 4, Jul-Set. 2018

DOI: https://doi.org/10.20873/uft.2447-4266.2018v4n4p27

apresentamos as reflexões e investigações sobre o potencial dos jogos digitais para os distintos cenários de aprendizagem. O dossiê inicia com o artigo QUANDO JOGO ATÉ ME ESQUEÇO DAS DORES: Jogos digitais como estratégia para reabilitação física, das autoras Ana Veloso, Tânia Ribeiro e Liliana Costa da Universidade de Aveiro. As autoras apresentam a análise do estado da arte das plataformas e jogos digitais indicados para reabilitação física e/ou similares.

Marcelo Vasconcellos, Flávia de Carvalho e Inesita de Araújo da FioCruz, Rio de Janeiro, no artigo "QUEM DEIXOU ISSO AQUI?!: Retórica procedimental e participação no desenvolvimento de um jogo em saúde dialogam com Bogost (2010) para analisar o processo de desenvolvimento do jogo "Quem deixou isso aqui?! Que foi produzido para crianças sobre prevenção de intoxicações domésticas.

O terceiro artigo de autoria de Elias Bitencourt da Universidade do Estado da Bahia, denominado QUEM GANHA QUANDO EU DURMO BEM?: A retórica procedimental como modo de midiatização dos cuidados de si na Fitbit Charge 2, uma tecnologia vestível que através de um aplicativo gamificado orienta o usuário com informações relacionadas com a atividade física, sono, batimentos cardíacos, dentre outros aspectos.

Em MULTIDISCIPLINARIDADE E O DESENVOLVIMENTO DE SERIOUS GAMES E SIMULADORES PARA EDUCAÇÃO E SAÚDE, de autoria Liliane Machado, Thaise Costa e Ronei Moraes da Universidade Federal da Paraíba, se constitui o quarto artigo. No presente artigo, os autores apresentam e discutem as etapas consideradas fundamentais no processo de desenvolvimento de serious games e simuladores voltados para educação e saúde na interface com a realidade virtual.

A segunda parte do primeiro dossiê apresenta as pesquisas relacionadas com jogos digitais e práticas gamificadas em cenários escolares e acadêmicos iniciando com o artigo SAFESKILL: um serious game para estudantes e profissionais de segurança do trabalho, Eliton de Freitas do Centro Universitário Senai - Cimatec, 


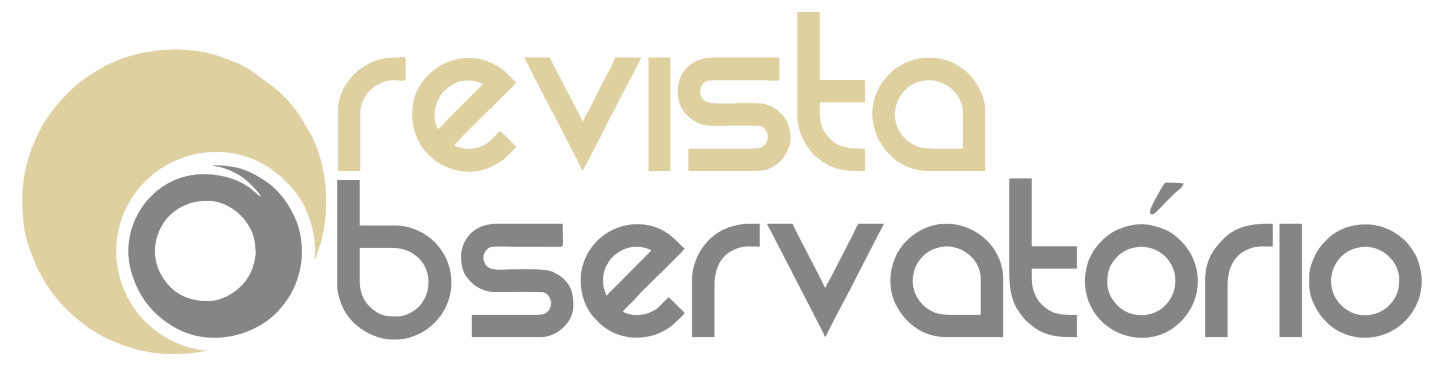

ISSN n² 2447-4266

Vol. 4, n. 4, Jul-Set. 2018

DOI: https://doi.org/10.20873/uft.2447-4266.2018v4n4p27

Lynn Alves da Universidade Federal da Bahia e Velda Torres da Universidade Federal da Bahia, discutem a abordagem Game Based Learning ou aprendizagem baseada em jogos digitais para subsidiar o desenvolvimento de Game Design Document ou Documento de Game Design de um jogo digital para mediar as aprendizagens dos alunos dos cursos de segurança do trabalho, sintonizado com a aplicação da Norma Regulamentadora $n^{\circ} 18$, que visa controlar as condições e meio ambiente de trabalho na indústria da construção civil.

Em JOGOS DIGITAIS MULTIMODAIS E RPG: Experiências no desenvolvimento da consciência ambiental a partir de recursos educacionais lúdicos, os autores Débora N. F. Barbosa, Rosemari L. Martins e Norberto Khun Júnior da Universidade Feevale/RS, apresentam e discutem experiências de desenvolvimento e a aplicação de um jogo digital multimodal de RPG (Role-playing game) que tem o objetivo de conscientizar alunos dos anos finais do Ensino Fundamental e do Ensino Médio de uma escola privada e de uma escola pública da região do Vale do Rio dos Sinos sobre o uso sustentável da água e dos recursos hídricos.

Adilson Rocha Ferreira e Deise Juliana Francisco da Universidade Federal de Alagoas no seu artigo A IMPLEMENTAÇÃO DOS EXERGAMES NO ÂMBITO DA SAÚDE MENTAL: percorrendo outros percursos e traçando outras formas de fazer o cuidado, socializam os resultados parciais da pesquisa realizada nos Centros de Atenção Psicossocial (CAPS) com pessoas que estão em processo de reabilitação psicossocial com a mediação dos jogos digitais.

O artigo GAMIFICAÇÃO NO ENSINO: casos bem sucedidos das autoras Inês Araújo e Ana Amélia Carvalho da Universidade de Coimbra, discute o polêmico conceito de gamificação, desmistificando-o e apontando possibilidades pedagógicas para os professores que "desejem aventurar-se no mundo da gamificação e proporcionar aos seus alunos novas experiências e emoções envolvendo-os no processo de aprendizagem". 


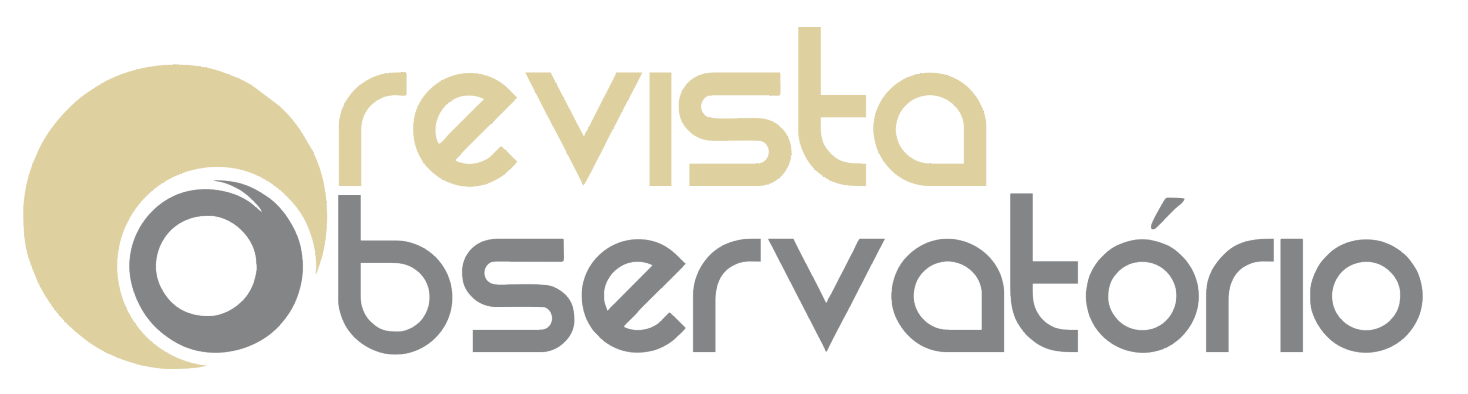

ISSN n² 2447-4266

Vol. 4, n. 4, Jul-Set. 2018

DOI: https://doi.org/10.20873/uft.2447-4266.2018v4n4p27

O Dossiê também apresenta uma ENTREVISTA com Espen J. Aarseth e Rune Nielsen, mediada por Luiz Adolfo Andrade da Universidade do Estado da Bahia na qual Aarseth e Nielsen, fundadores do Games Studies ${ }^{1}$ e principais pesquisadores europeus na área de jogos digitais dialogam sobre temas importantes que tencionam a área, inclusive no que se refere aos jogos voltados para saúde.

É importante ressaltar que embora as pesquisas em torno do tema proposto, especialmente os games e gamificação tenham crescido nos últimos anos tivemos apenas uma Revista Plurais: Revista Multidisciplinar da UNEB, com o tema Games e Cultura, publicada em mai/ago de 2010 e organizada por Lynn Alves dedicada ao tema e em fevereiro de 2017 foi criada a Ludica - International Journal of Games Studies2. Logo a publicação aqui apresentada trará contribuições significativas para a área dos jogos digitais e suas interfaces com a educação e saúde, se constituindo em um espaço para socialização, discussões e reflexões em torno da temática proposta, a partir das contribuições investigações luso-brasileiras.

Assim, o primeiro dossiê contribui para a construção de um olhar diferenciado e crítico das interações com os ambientes interativos, sejam games, aplicativos ou simuladores, bem como a construção de estratégias gamificadas na interface saúde e educação.

No segundo dossiê intitulado NOTICIABILIDADE o foco é a construção de noticias. Construir uma notícia é uma ação fundamental do jornalista. Uma ação mais tensa no mundo da pós-verdade, das fake news, das inovações, do algoritmogatekeeper. Com o livre acesso para a publicação, todos nós podemos ser 'produtores de conteúdo', mesmo nas redes sociais. Publica-se de tudo: de cena cotidiana a acidente aéreo. Há mais horizontalidade (Deuze; Witschge, 2016), inclusive na relação com especialistas. No entanto, este fabrico, que gera uma gama

\footnotetext{
${ }^{1}$ http://gamestudies.org/1801

2 https://ludicajournal.com/index.php/ludica
} 


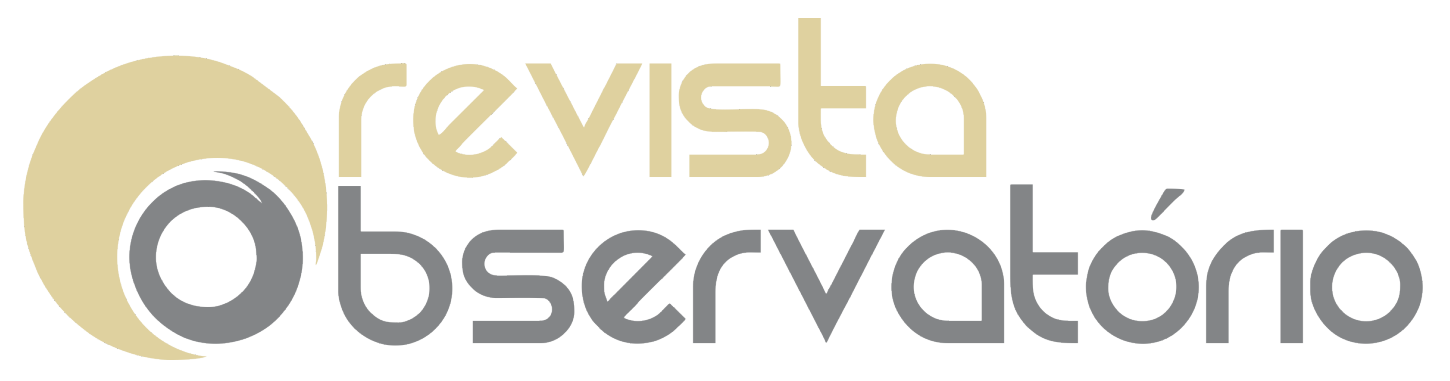

ISSN n² 2447-4266

Vol. 4, n. 4, Jul-Set. 2018

DOI: https://doi.org/10.20873/uft.2447-4266.2018v4n4p27

de produtos, provoca também desarranjo na condição de noticiabilidade. As competências de seleção e hierarquização estão em cheque.

Os produtos do que se chama hoje de mídia tradicional 'davam as cartas'. O tom atual é de: "isso não se tolera mais". Os públicos segmentados que o digam. Chega-se a pensar: "Será que a força do público-alvo não estabeleceria parâmetros de relevância?". Dizer sim seria sair de um polo para o outro. Então, quem, onde e como se estabelecem os parâmetros? Em um contexto de diluição do jornalismo pela multiplicação das ferramentas autopublicação, das iniciativas de jornalismo cidadão, da circulação de notícias falsas nas redes sociodigitais, retomar os trabalhos sobre noticiabilidade e seus desdobramentos na cultura jornalística e de modalidades de gestão das relações com os públicos e as fontes poderia ser uma estratégia interessante de compreensão das reconfigurações da prática jornalística nos dias atuais.

Este é um dos três grandes questionamentos deste dossiê temático ${ }^{3}$. O segundo, de ordem teórica, revela as preocupações em relação às diferentes apropriações do conceito de noticiabilidade. Inspirado na tradição norte-americana da sociologia dos emissores dos anos 1970-1980, esta perspectiva se difunde por aqui principalmente por meio de manuais e textos de condensação de teorias (Cf. Traquina, 2004, 2005; 1993; Wolf, 1995) e passa ser amplamente empregado nos estudos sobre o jornalismo brasileiro (Strelow, 2011; Meditsch \& Segala, 2004). No entanto, de qual noticiabilidade estamos falando? Sem entrar na tentação normativa de apontar as formas "corretas" de se utilizar o conceito, um dos objetivos deste dossiê foi justamente o de mapear as diferentes acepções que a noticiabilidade adquire nos meios acadêmicos brasileiro e anglo-saxão. Assim, buscou apontar pistas para se problematizar as modalidades de leitura e formulação nativa do conceito.

3 O dossiê dá continuidade a duas propostas de comunicações coordenadas realizadas nos Congressos da SBPJor de 2016 e 2017. Parte dos artigos propostos nesta edição foram discutidos e, depois de atualizados, finalizados para o dossiê que aqui está. 


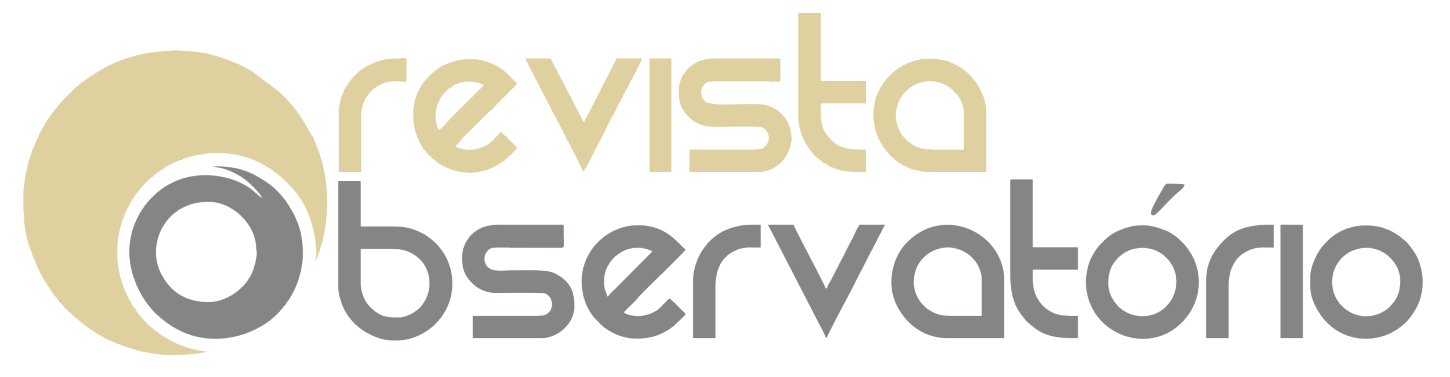

ISSN n² 2447-4266

Vol. 4, n. 4, Jul-Set. 2018

DOI: https://doi.org/10.20873/uft.2447-4266.2018v4n4p27

A terceira preocupação está vinculada às possíveis evoluções da noticiabilidade, seja por meio dos tensionamentos provocados pelas mídias digitais e pelas chamadas mudanças estruturais do jornalismo (Cf. Pereira e Adghirni, 2011; Jorge, 2013), seja pela incorporação de outras perspectivas teóricas capazes de enriquecer o conceito e sua capacidade heurística. Neste ponto, pensamos particularmente em sua utilização em projetos que ambicionem a construção de teoria(s) da notícia ou do jornalismo (Cf. Sousa, 2001; McCombs e Shaw, 2001). Mas também na possibilidade de recorrer aos fundamentos da noticiabilidade em usos mais disruptivos e interdisciplinares, aplicando-a à leitura de outros fenômenos, como a sociologia profissional dos jornalistas (Zelizer, 1993), a comunicação organizacional (Monteiro, 2003), as relações entre mídia e política (Guazina, 2011).

Para responder a essas preocupações, o dossiê reúne dois dos maiores especialistas brasileiros no tema, jovens pesquisadores que trazem inovação para a discussão, além de sistematizações de leitura e aplicação para estudar noticiabilidade. Abrindo o dossiê, Alfredo Vizeu, autor da primeira aplicação prática de newsmaking no Brasil no livro Decidindo o que é Notícia, traz releitura e atualização do trabalho 20 anos depois em artigo produzido com a mestre, Flora Leite, a quem orientou recentemente, no artigo DECIDINDO O QUE É NOTÍCIA: 20 anos depois. Com o objetivo revisitar a pesquisa, resultado de mais de 15 anos de trabalho no jornalismo, da vida acadêmica como uma nova profissão e de poder pensar o jornalismo como um campo de conhecimento, o artigo tem a intenção de apresentar algumas mudanças no jornalismo atual que não se faziam presentes em 1997.

Gislene Silva, autora do artigo referência Para pensar critérios de noticiabilidade, publicado em 2005 em Estudos de Jornalismo e Mídia, traz um ensaio com a motivação de marcar novamente a diferença entre os conceitos de valoresnotícia e critérios de noticiabilidade, insistir no não reducionismo do conceito de 


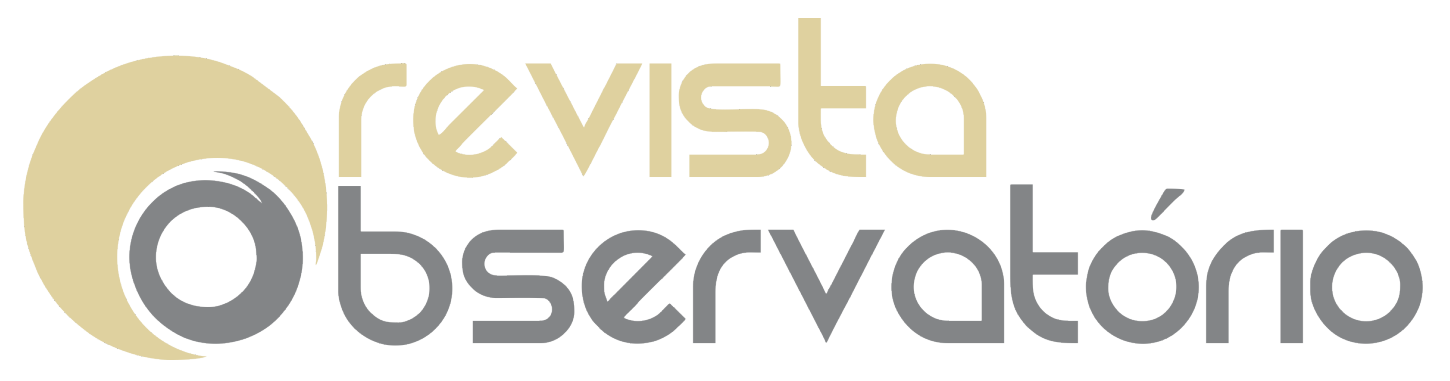

ISSN n² $2447-4266$

Vol. 4, n. 4, Jul-Set. 2018

DOI: https://doi.org/10.20873/uft.2447-4266.2018v4n4p27

noticiabilidade e explicitar com mais vigor a não simplificação a respeito de valoresnotícia, um dos tantos critérios de noticiabilidade. Gislene aceitou o desafio de voltar a questões tratadas no trabalho de 2005 para expor com mais ênfase a rede complexa em que um acontecimento, entre tantos, ganha potência para ser transfigurado em acontecimento jornalístico, no artigo intitulado A ENGRENAGEM DA NOTICIABILIDADE NO MEIO REDEMOINHO.

No artigo VALORES NOTÍCIA: uma proposta de análise, Lia Seixas traz uma proposta de análise de noticiabilidade: o critério surgiria da associação entre atributo e produto ou atributo e público-alvo, em relação às funções da instituição jornalística e saber social compartilhado em dado momento e espaço. Através da comparação entre 12 obras clássicas e frequentemente consultadas no Brasil, a pesquisadora sugere uma redução das classificações de critérios e uma maneira de analisa-los nos produtos jornalísticos, ao mesmo tempo em que testa metodologicamente esta proposta em pesquisa realizada atualmente com um dos autores deste dossiê, professor Fábio Pereira ${ }^{4}$. O corpus-base atravessa três mídias, impressa, digital e televisual.

Já Marcos Paulo, organizador de Critérios de noticiabilidade - problemas conceituais e aplicações em 2014 juntamente com Gislene Silva e Mario Fernandes, produziu com sua orientanda de mestrado, Raquel Jeronymo, artigo intitulado A CONSTRUÇÃO CULTURAL DE CRITÉRIOS NOTICIOSOS EM CONTEXTOS REGIONAIS: reflexões teórico-metodológicas a partir dos jornais de Corumbá (MS) com objetivo de promover uma discussão teórico-metodológica sobre a construção cultural dos critérios de noticiabilidade no jornalismo e sua operacionalização em realidades regionalizadas. Reforçam a concepção de noticiabilidade como constructo de natureza cognitiva, que traz da sua tese, bem como acentuam a pertinência do

${ }^{4}$ Intitulada Mídia e espaço público: desafios da democracia em nível subnacional (2007-2014), a pesquisa é coordenada por Liziane Guazina (UNB), com Julián Durazco (UQAM), Fábio Pereira (UNB) e Lia Seixas (UFBa). Financiamento da FAP-DF:10534.56.33438.10042016. 


\section{Observatório}

ISSN n² 2447-4266

Vol. 4, n. 4, Jul-Set. 2018

DOI: https://doi.org/10.20873/uft.2447-4266.2018v4n4p27

conceito no interior das mediações jornalísticas da vida cotidiana. Os autores sugerem uma tipologia de análise própria da imprensa interiorana, valendo-se dos resultados de uma pesquisa mais ampla sobre os critérios de noticiabilidade nos jornais de Corumbá (MS).

Fábio Pereira, em AS NOTÍCIAS COMO PRÁTICA COLETIVA E CONVENCIONAL: a abordagem beckeriana aplicada aos estudos do jornalismo, explora a noticiabilidade por sua dimensão coletiva, trazendo uma abordagem interacionista para a compreensão da atividade jornalística enquanto prática dinâmica e coletiva. $\mathrm{O}$ artigo propõe a aplicação dos conceitos de mundo social e de convenções, originários da sociologia das formas de representação da sociedade de Howard Becker, aos estudos de jornalismo. $\mathrm{O}$ autor defende a ideia de que a noticiabilidade consistiria em um sistema de convenções que fornece as bases para um processo mais amplo de negociação entre jornalistas, fontes, públicos e demais colaboradores em torno produção jornalística.

No mesmo sentido de compreender o público no seu cotidiano e interesse manifesto, Ana Brambilla, no artigo HOMOGENEIDADE E ENDOGENIA NOS INTERESSES DE JORNALISTAS DES-CONECTAM VALOR NOTÍCIA E POPULAÇÃO, traZ parte do resultado de sua tese de doutorado, recém defendida. A pesquisadora comparou os níveis de interesse de um grupo de jornalistas com um grupo de 650 indivíduos de diferentes perfis demográficos por conteúdos que circulam nas redes sociais. O foco são as discrepâncias entre visões de mundo de jornalistas e de usuários de redes sociais podem ser responsáveis por uma crise de relevância mascarada pela dicotomia entre interesse público e interesse do público. Será que a demanda informativa da população não tenha mudado nos últimos quatro séculos?

$O$ artigo A NOTICIABILIDADE A PARTIR DO AUDIOVISUAL: da mídia tradicional à recirculação em redes sociais digitais, de Leila Nogueira, especialista em televisão e imagem em movimento, busca desenvolver algumas ideias sobre o audiovisual 


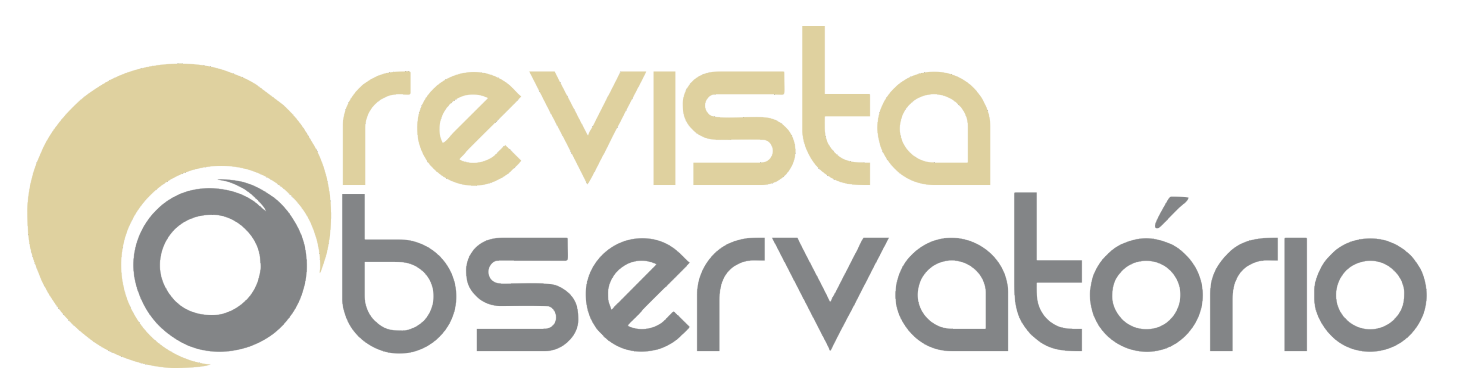

ISSN n 2447-4266

Vol. 4, n. 4, Jul-Set. 2018

DOI: https://doi.org/10.20873/uft.2447-4266.2018v4n4p27

noticioso na contemporaneidade. Tendo como base sua tese defendida em 2017, a autora discute a especificidade da notícia construída a partir da linguagem audiovisual e sua relação com valores-notícia e critérios de noticiabilidade. A partir do caso de Fabiane Maria de Jesus, morta em 2014 após ser confundida com um retrato falado que circulava nas redes sociais digitais, Leila investigou a utilização de conteúdo "amador" na composição das narrativas noticiosas.

Com foco na televisual em sua dissertação defendida em abril de 2017, Jussara Borges, no artigo CRITÉRIOS DE NOTICIABILIDADE NO BRASIL E NO MUNDO, traz aqui uma ferramenta de estudo lucrativa para quem pesquisa noticiabilidade: estado da arte dos estudos de noticiabilidade no Brasil e no mundo. Além de contextualizar as obras e relacioná-las, Jussara discute as conceituações e classificações. A pesquisadora apontou valores-notícia mais utilizados em determinado período de tempo e constatou que há um número reduzido de pesquisas ao passo que as classificações, muitas vezes, se repetem.

Este conjunto de artigos é incapaz de esgotar o tema e os possíveis desdobramentos de uma problematização mais aprofundada em relação à noticiabilidade. Contudo, ele pode ser uma porta de entrada para um debate de fundo em relação às possibilidades e limites de sua utilização no atual estágio das pesquisas em jornalismo no Brasil. De fato, a despeito de sua antiguidade e relativa popularização, acreditamos que esse conceito ainda não perdeu sua capacidade de fornecer explicações originais e empiricamente aplicáveis a objetos do jornalismo e de disciplinas conexas. Esperamos que os leitores também partilhem desse nosso interesse e entusiasmo.

Na seção TEMAS LIVRES, trazemos a produção de Jocyleia Santana dos Santos e Erick Henrique Goes Silva intitulada TDICS E GAMES NO ENSINO MÉDIO INOVADOR: memórias de professores criativos. No artigo, os autores apresentam às memórias de professores colaboradores do Programa Ensino Médio Inovador (PEMI) 


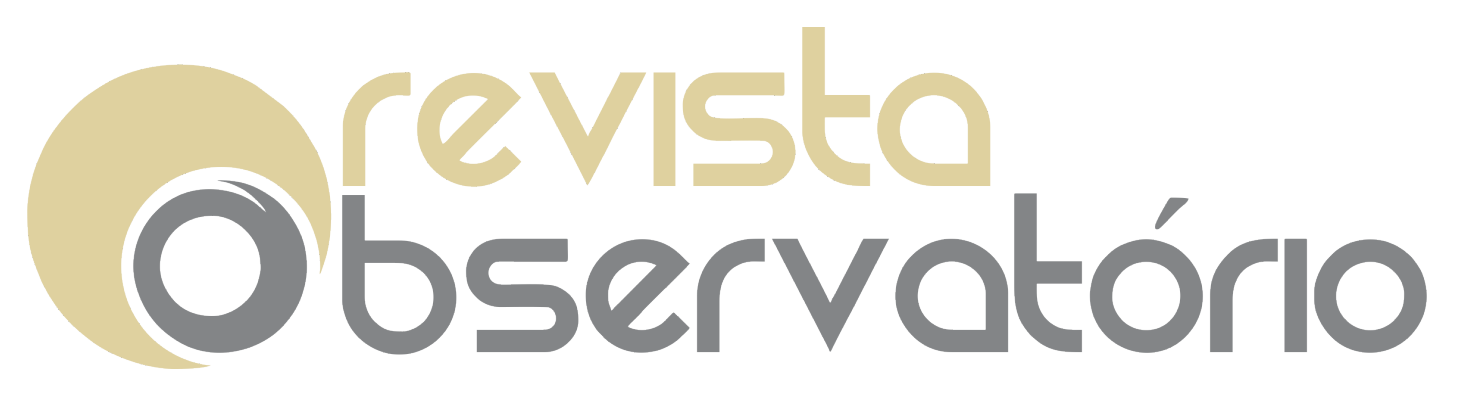

ISSN n 2447-4266

Vol. 4, n. 4, Jul-Set. 2018

DOI: https://doi.org/10.20873/uft.2447-4266.2018v4n4p27

da Escola Estadual Frederico José Pedreira Neto da rede pública de ensino de Tocantins, localizado na cidade de Palmas-TO.

No artigo A COMUNICAÇÃO ON LINE NO ENSINO SUPERIOR COMO RECURSO DIDÁTICO NA PESQUISA EM EDUCAÇÃO, Karla Cristina Silva Sousa analisa as possibilidades e limites da construção em pesquisas em educação de ferramentas on line para coletas de dados. Discute sobre os aspectos da pesquisa enquanto campo de domínio da razão imperialista que produz uma hierarquia social dos objetos, por meio das artimanhas da razão nos lugares comuns da pesquisa acadêmica.

Já no artigo INSTITUCIONALIZAÇÃO DA PESQUISA SOBRE CRIANÇA E ADOLESCENTE EM JORNALISMO E EM COMUNICAÇÃO NOS ANOS 1990 E 2000, Robson Dias, Daniel Gonçalves de Oliveira, Victor Márcio Laus Reis Gomes, João José de Azevedo Curvello, Luiza Mônica de Assis Silva e Alberto Marques Silva inventariam 37 dissertações e 8 teses fazendo um balanço da pesquisa sobre o tema. O intuito é de munir pesquisadores que se interessem pela cronologia de estudo do tema nas Ciências Sociais Aplicadas e pela sua institucionalização na Ciência em Jornalismo e em Comunicação no Brasil.

Em NARRATIVA JORNALÍSTICA SUL-MATO-GROSSENSE: a reocupação das fazendas pelos índios Guarani Kaiowá no município de Antônio João, os autores Carolina Silva Costa e Mario Luiz Fernandes analisam o discurso de representação do indígena, na reportagem veiculada no dia 29 de agosto de 2015, no jornal Correio do Estado sobre o clima de guerra vivido no município de Antônio João, Mato Grosso do Sul, devido a ação de reocupação das fazendas pelos indígenas Guarani Kaiowá, Terra Ñande Ru Marangatu.

No artigo AS INTERVENÇÕES ARTÍSTICAS URBANAS NO CIRCUITO DA ARTE EM RORAIMA E O POTENCIAL COMUNICATIVO DOS SABERES ARTÍSTICOS AMAZÔNICOS, Leila Adriana Baptaglin e Vilso Junior Chierentin Santi discutem como as intervenções artísticas urbanas comunicam ao expectador Roraimense apresenta- 


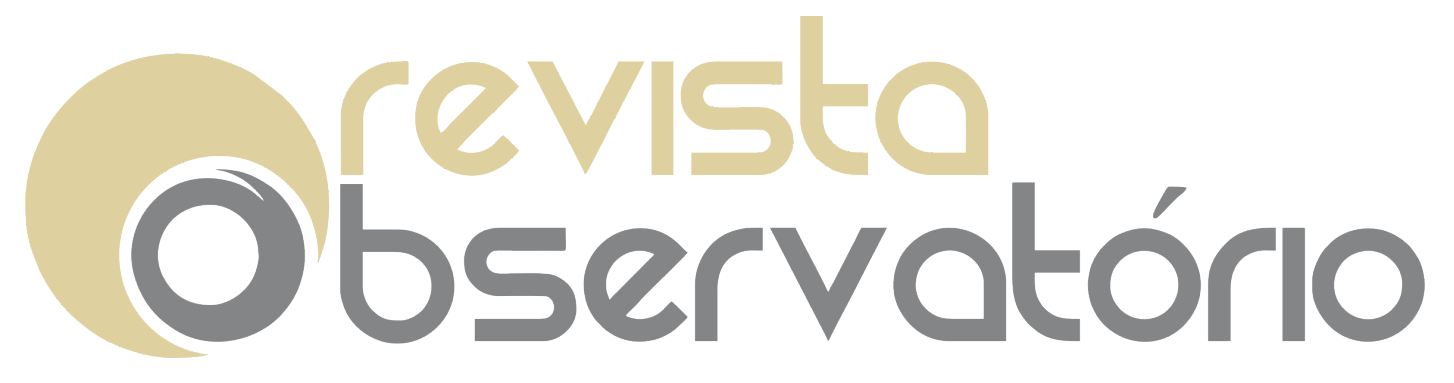

ISSN n 2447-4266

Vol. 4, n. 4, Jul-Set. 2018

DOI: https://doi.org/10.20873/uft.2447-4266.2018v4n4p27

se como o foco de discussão deste estudo. Para dar conta desse objetivo, foram realizadas investigações teóricas pautadas na compreensão do cenário artístico contemporâneo, a partir dos estudos de Cauquelin (2005) e Cocchiarale (2004); e das especificidades roraimense, dando destaque à representação artística dos saberes locais, com os estudos de Gonçalves (2017) e Silva (2017), também com a apropriação dos conceitos de circuito da cultura de Johnson (1999) e Nessbaumer (2000), no sentido de estabelecer uma proposta de discussão acerca do que chamamos Circuito da arte.

Em A ESCOLA E O MUNDO: pressupostos para a integração da atualidade na sala de aula, Patrícia Silveira apresneta um estudo com o propósito de debater sobre como a escola ajuda as crianças a conhecer o mundo mediato e o imediato. Através da administração de questionários a uma amostra de 690 crianças portuguesas (8-12 anos), os resultados permitem concluir que a escola não integra os assuntos da sociedade e do mundo, na sala de aula, embora as crianças demonstrem o desejo de que estes temas possam ser abordados neste contexto.

No artigo IMPERATRIZ, O POVO E A FAMA: a violência imaginária no jornal O Progresso (MA), Denise Cristina Ayres Gomes, Letícia Feitosa Barreto, Pollyana da Silva Galvão, André Wallyson, Lanna Luiza Silva Bezerra e Laura Glapinski Zacca discute a violência no jornal maranhense $O$ Progresso (OP) a partir das teorias do imaginário (MAFFESOLI, 2001; 2003a; SILVA, 2012). A pesquisa é composta por 79 ocorrências dos anos de 1970 e 1971, onde a violência imaginária é tratada como um constructo simbólico resultante da ação jornalística sobre a realidade.

Já em MEMÓRIAS E NARRATIVAS: a vocação comunitária do Centro de Estudos e Pesquisas em Reabilitação (CEPRE/FCM/Unicamp) por meio da história oral, Ricardo Santhiago e Giovanna Cristina Bertelli de Lacerda apresentam os resultados de uma pesquisa sobre a trajetória e a atuação comunitária do Centro de Estudos e Pesquisas em Reabilitação "Prof. Dr. Gabriel O. S. Porto" (CEPRE), que integra a Faculdade de 


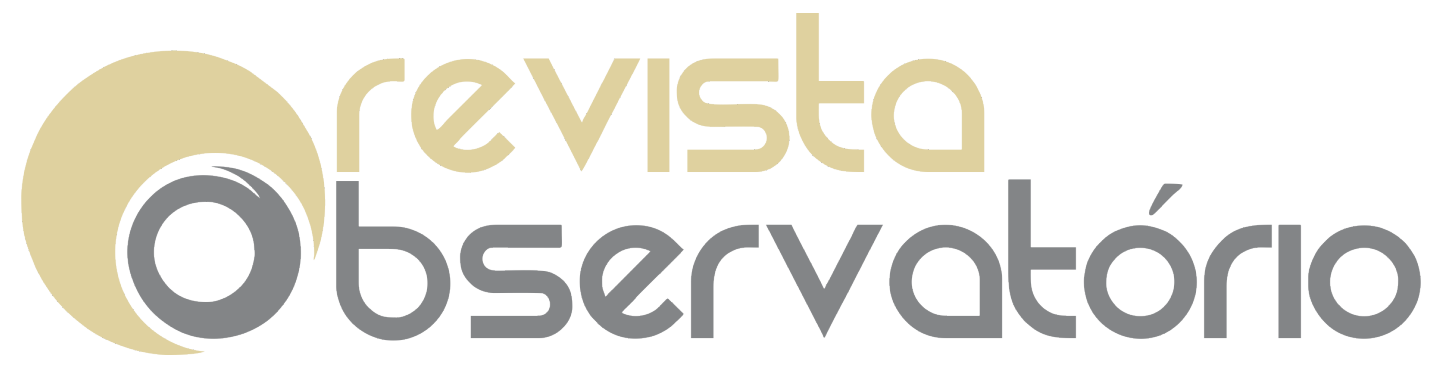

ISSN n² 2447-4266

Vol. 4, n. 4, Jul-Set. 2018

DOI: https://doi.org/10.20873/uft.2447-4266.2018v4n4p27

Ciências Médicas da UNICAMP. Por meio de narrativas orais de docentes e outros profissionais que foram e são responsáveis pela constituição e pelo desenvolvimento do CEPRE, discute-se a história e a memória do Centro, principalmente considerando-se sua definição inicial como um instituto voltado a atividades de prestação de serviço em saúde às comunidades.

Em PROPAGANDA ELEITORAL NAS NOTíCIAS: interfaces entre jornalismo e Programa Eleitoral Gratuito nas eleições para o governo do Maranhão, Li-Chang Shuen Cristina Silva Sousa traz os resultados referentes ao eixo "Telejornalismo e HGPE" da pesquisa Mediatização das Eleições de 2014 no Maranhão, cujo objetivo geral foi identificar os padrões discursivos de construção da viabilidade eleitoral e capital político do candidato Edson Lobão Filho (PMDB) ao governo estadual. O objetivo deste paper específico foi estudar a permeabilidade entre a lógica política propagada no HGPE-Lobão Filho e o discurso político-jornalístico do JMTV1.

Em EDUCAÇÃO SOCIOAMBIENTAL, HISTÓRIA ORAL E FORMAÇÃO DOCENTE: A construção de um projeto de ensino com pescadores artesanais, Juniele Rabelo Almeida e Ademas Pereira da Costa Junior refletem sobre a construção de um projeto de ensino para educação básica no entrecruzamento das dimensões metodológicas do trabalho com educação socioambiental e história oral. A prática e pesquisa em ensino de História pode integrar saberes escolares e comunitários contribuindo para a formação de professores em nível superior e visando a melhoria da qualidade da educação pública.

Já em A ESCRITA: uma prática movida pela busca da melhor adequação da execução à intenção, Maria da Graça Lisboa Castro Pinto o objeto é desmontar o processo da escrita-composição evidenciando a importância de que se reveste o desdobramento do escritor/autor em diferentes papéis, que vão de leitor a editor, passando por investigador, descobridor, revisor e crítico. Observa-se, então, a diferença entre o exercício de todas essas funções pelo próprio autor e a sua 


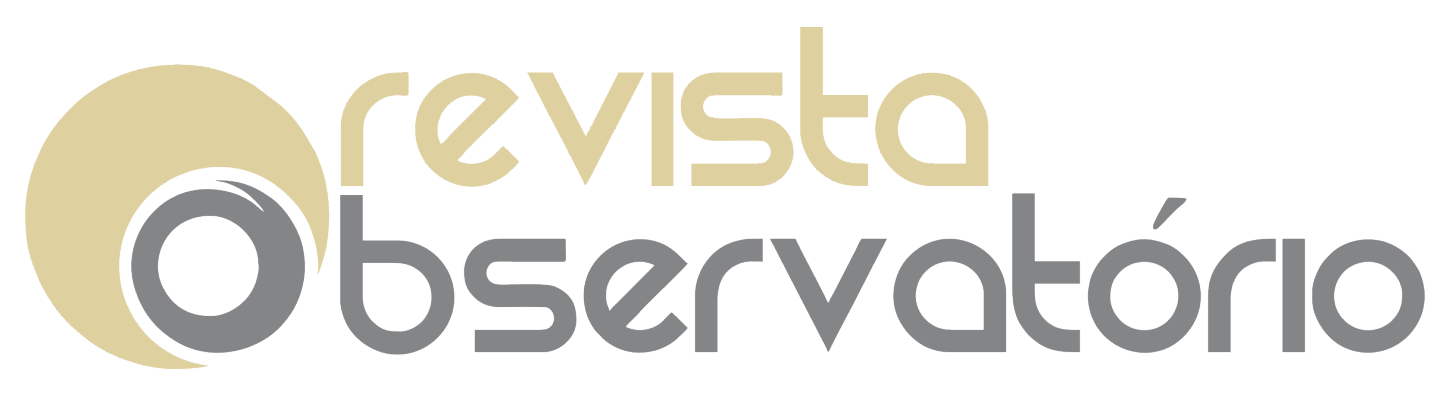

ISSN n² 2447-4266

Vol. 4, n. 4, Jul-Set. 2018

DOI: https://doi.org/10.20873/uft.2447-4266.2018v4n4p27

assunção por diferentes agentes numa ótica da construção da obra pela divisão do trabalho, conforme propõe o narrador de S. Bernardo, de Graciliano Ramos, no início do romance.

Em EDUCAÇÃO PARA O TRÂNSITO: metodologia e estratégias para atuação junto aos acadêmicos da universidade da maturidade na cidade de Araguaína/TO, Cleide de Sousa Morais e Neila Barbosa Osório discutem o compreender e conviver com idosos de maneira a proporcionar-lhes um trânsito mais seguro. O problema exposto consiste em descrever a elaboração de um método desenvolvido na disciplina de Educação para o Trânsito aos velhos da Universidade da Maturidade.

No artigo EXISTEM ELEITORES QUE COMERCIALIZAM O VOTO?, de Adriano Oliveira, Carlos Gadelha e Simara Costa, foge do lugar-comum, ao mostrar que o comércio do voto existe, inclusive entre eleitores que declaram que não desejam mudar a sua escolha eleitoral às vésperas da eleição.

E, finalizando a seção, o artigo "NOVAS" CONFIGURAÇÕES FAMILIARES NA CONTEMPORANEIDADE - UMA (RE) LEITURA DE MEUS DOIS PAIS, DE WALCYR CARRASCO (2010), Rubenilson Pereira de Araujo versa sobre as configurações familiares na contemporaneidade, sobretudo no que toca na possível transição entre heterossexualidade e homoafetividade em relação às orientações sexuais. $\mathrm{O}$ aporte teórico se centra nos estudos de gênero e se volta para os estudos literários com análise de um corpus na obra de literatura brasileira infantil, de Walcyr Carrasco denominada Meus dois pais (2010).

Na seção ENTREVISTAS, como já informado trazemos uma conversa com Espen J. Aarseth e Rune Nielsen, mediada por Luiz Adolfo Andrade da Universidade do Estado da Bahia na qual Aarseth e Nielsen, fundadores do Games Studies ${ }^{5}$ e principais pesquisadores europeus na área de jogos digitais dialogam sobre temas

\footnotetext{
${ }^{5}$ http://gamestudies.org/1801
} 


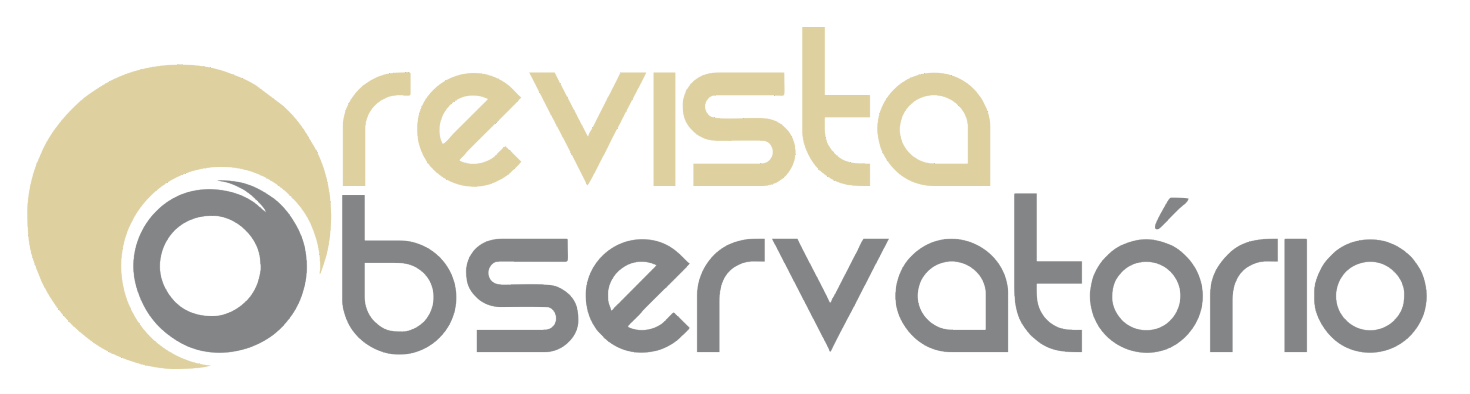

ISSN n² 2447-4266

Vol. 4, n. 4, Jul-Set. 2018

DOI: https://doi.org/10.20873/uft.2447-4266.2018v4n4p27

importantes que tencionam a área, inclusive no que se refere aos jogos voltados para saúde.

E, finalizando o número, na seção VISUALIDADES, temos três produções: a primeira intitulada GAMBIARRAS PEDALANTES: pesquisas em trânsito, de Sheila Hempkemeyer discute a subjetivação contemporânea, estratégias de reexistência, vendo a educação como um evento dinâmico e permanente. Vê na bicicleta seu potencial educativo e ambiental, apoiando-se nos Estudos Culturais e nas contribuições coletivas que estão ligadas por referências teóricas. $O$ estudo potencializa narrativas ficcionais e sua inventividade. Por meio de inventário de imagens e narrativas, analisa os efeitos educativos da bicicleta na vida das pessoas.

A segunda, intitulada UM MAPA É UMA COISA IMPOSSÍVEL, de Karina Rousseng Dal Pont, onde partilha reflexões sobre a trajetória formativa em âmbito doutoral por meio da arte e da educação geográfica com o uso da cartografia escolar.

A terceira, intitulada TRAKINAGEM: cinema e educação na escola, de Cristiano Barbosa apresenta o projeto TraKinagem - Mostra de Cinema e Educação que tem o objetivo de produzir e exibir filmes realizados em contextos escolares. Em oficinas com alunos e professores se experimenta um processo de filmagem-aprendizagem que explora de forma criativa os componentes da imagem na construção de filmes de curta duração, utilizando os conceitos de encontro, devir e cartografia de Gilles Deleuze e Félix Guattari.

Isto posto, sejam todos/as bem-vindos/as a temática deste número, que objetiva, enquanto plataforma de análises, ser uma caixa ressoante de reflexões, problematizações, teorizações e contradições. Leia, assista, compartilhe e indique a leitura dos artigos produzidos no n. 4 de 2018 da Revista Observatório.

Salvador-BA, Recife-PE, Tupã-SP, Palmas-TO, julho de 2018. 


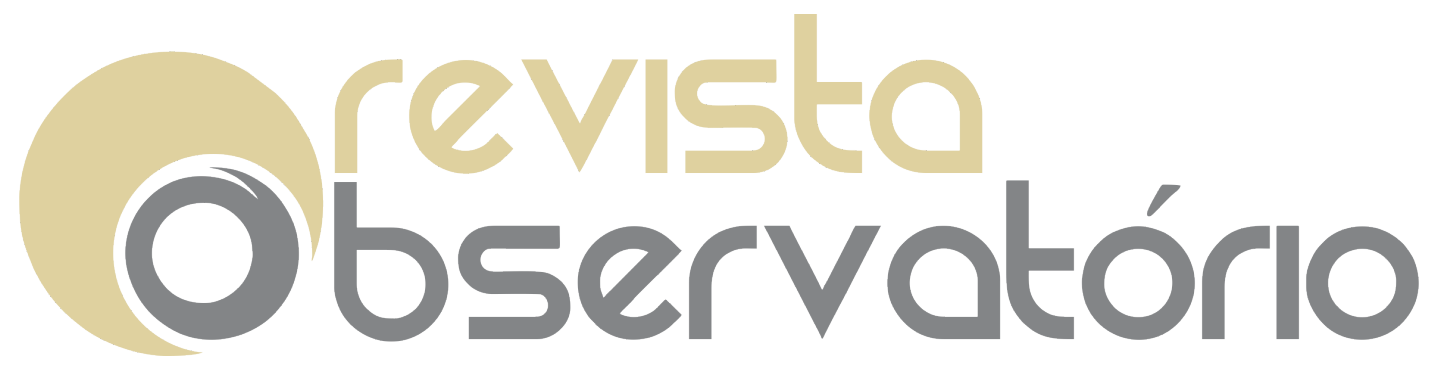

ISSN n² 2447-4266

Vol. 4, n. 4, Jul-Set. 2018

DOI: https://doi.org/10.20873/uft.2447-4266.2018v4n4p27

Editores convidados/ Guest Editors/ Editores invitados

Profa. Dra. Lynn Alves, Universidade Federal da Bahia (UFBA), Brasil.

Profa. Dra. Isa Neves, Universidade Federal da Bahia (UFBA), Brasil.

Profa. Dra. Lia Seixas, Universidade Federal da Bahia (UFBA), Brasil.

Prof. Dr. Alfredo Vizeu, Universidade Federal de Pernambuco (UFPE), Brasil.

Editor Geral / Chief Editor / Editor general

Prof. Dr. Nelson Russo de Moraes, Universidade Estadual Paulista Júlio de Mesquita Filho (UNESP), Brasil.

Prof. Dr. Francisco Gilson Rebouças Porto Junior, Universidade Federal do Tocantins (UFT), Brasil.

\section{Referências}

ALMEIDA, J. R.; COSTA JUNIOR, A. P. DA. EDUCAÇÃO SOCIOAMBIENTAL, HISTÓRIA ORAL E FORMAÇÃO DOCENTE: A construção de um projeto de ensino com pescadores. Revista Observatório, v. 4, n. 4, p. 738-762, 29 jun. 2018.

ALVES, J. B. CRITÉRIOS DE NOTICIABILIDADE NO BRASIL E NO MUNDO. Revista Observatório, v. 4, n. 4, p. 468-499, 29 jun. 2018.

ANDRADE, L. A. GAME STUDIES ENCONTRAM JOGOS PARA SAÚDE: Uma entrevista com Espen Aarseth e Rune Nielsen. Revista Observatório, v. 4, n. 4, p. 858-873, 29 jun. 2018.

ARAÚJO, I.; CARVALHO, A. A. GAMIFICAÇÃO NO ENSINO: casos bemsucedidos. Revista Observatório, v. 4, n. 4, p. 246-283, 29 jun. 2018.

AYRES GOMES, D. C.; BARRETO, L. F.; GALVÃO, P. DA S.; WALLYSON, A.; BEZERRA, L. L. S.; ZACCA, L. G. IMPERATRIZ, O POVO E A FAMA: a violência imaginária no jornal O Progresso (MA). Revista Observatório, v. 4, n. 4, p. 660-683, 29 jun. 2018. 


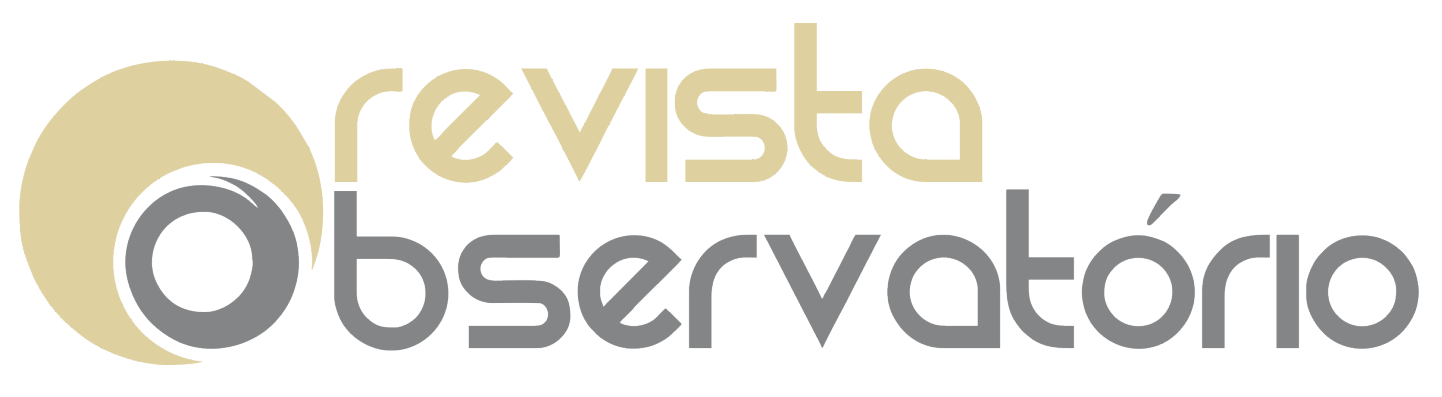

ISSN n² 2447-4266

Vol. 4, n. 4, Jul-Set. 2018

DOI: https://doi.org/10.20873/uft.2447-4266.2018v4n4p27

BAPTAGLIN, L. A.; CHIERENTIN SANTI, V. J. AS INTERVENÇÕES ARTÍSTICAS URBANAS NO CIRCUITO DA ARTE EM RORAIMA E O POTENCIAL COMUNICATIVO DOS SABERES ARTíSTICOS AMAZÔNICOS. Revista Observatório, v. 4, n. 4, p. 615-637, 29 jun. 2018. BARBOSA, C. TRAKINAGEM: cinema e educação na escola. Revista Observatório, v. 4, n. 4, p. 893-898, 29 jun. 2018.

BITENCOURT, E. C. QUEM GANHA QUANDO EU DURMO BEM?: a retórica procedimental como modo de midiatização dos cuidados de si na Fitbit Charge 2. Revista Observatório, v. 4, n. 4, p. 113-148, 29 jun. 2018.

BOGOST, Ian. Persuasive Games: The Expressive Power of Videogames (MIT Press). EUA, 2010

BRAMBILLA, A. M. HOMOGENEIDADE E ENDOGENIA NOS INTERESSES DE JORNALISTAS DES-CONECTAM VALOR NOTÍCIA E POPULAÇÃO. Revista Observatório, v. 4, n. 4, p. 420-444, 29 jun. 2018.

DAL PONT, K. R. UM MAPA É UMA COISA IMPOSSÍVEL. Revista Observatório, v. 4, n. 4, p. 885-892, 29 jun. 2018.

DE ARAUJO, R. P. "NOVAS" CONFIGURAÇÕES FAMILIARES NA CONTEMPORANEIDADE - UMA (RE) LEITURA DE MEUS DOIS PAIS, DE WALCYR CARRASCO (2010). Revista Observatório, v. 4, n. 4, p. 833-857, 29 jun. 2018.

Deuze, Mark; Witschge, Tamara. O que o jornalismo está se tornando. Dossiê práticas jornalísticas. Parágrafo. Jul/dez. V. 4.N²2. 2016.

DIAS, R.; DE OLIVEIRA, D. G.; LAUS REIS GOMES, V. M.; DE AZEVEDO CURVELLO, J. J.; SILVA, L. M. DE A.; SILVA, A. M. INSTITUCIONALIZAÇÃO DA PESQUISA SOBRE CRIANÇA E ADOLESCENTE EM JORNALISMO E EM COMUNNICAÇÃO NOS ANOS 1990 E 2000. Revista Observatório, v. 4, n. 4, p. 571-614, 29 jun. 2018.

FERRARI BARBOSA, D. N.; MARTINS, R. L.; JUNIOR, N. K. JOGOS DIGITAIS MULTIMODAIS E RPG: Experiências no desenvolvimento da consciência ambiental a partir de recursos educacionais lúdicos. Revista Observatório, v. 4, n. 4, p. 201-228, 29 jun. 2018.

FERREIRA, A. R.; FRANCISCO, D. J. A IMPLEMENTAÇÃO DOS EXERGAMES NO ÂMBITO DA SAÚDE MENTAL: percorrendo outros percursos e traçando outras formas de fazer o cuidado. Revista Observatório, v. 4, n. 4, p. 229-245, 29 jun. 2018.

FLEURY, Afonso; NAKANO, Davi; CORDEIRO, J. H. D. O. Mapeamento da indústria brasileira e global de jogos digitais. São Paulo: GEDIGames/USP, 2014.

FREITAS, E. E. B. DE; ALVES, L. R. G.; TORRES, V. G. A. SAFESKILL: um serious game para estudantes e profissionais de segurança do trabalho. Revista Observatório, v. 4, n. 4, p. 173-200, 29 jun. 2018.

HEMPKEMEYER, S. GAMBIARRAS PEDALANTES: pesquisas em trânsito. Revista Observatório, v. 4, n. 4, p. 874-884, 29 jun. 2018.

JORGE, T. M. Mutação no jornalismo. Como a notícia chega à internet. Brasília: EdUnB, 2013. 


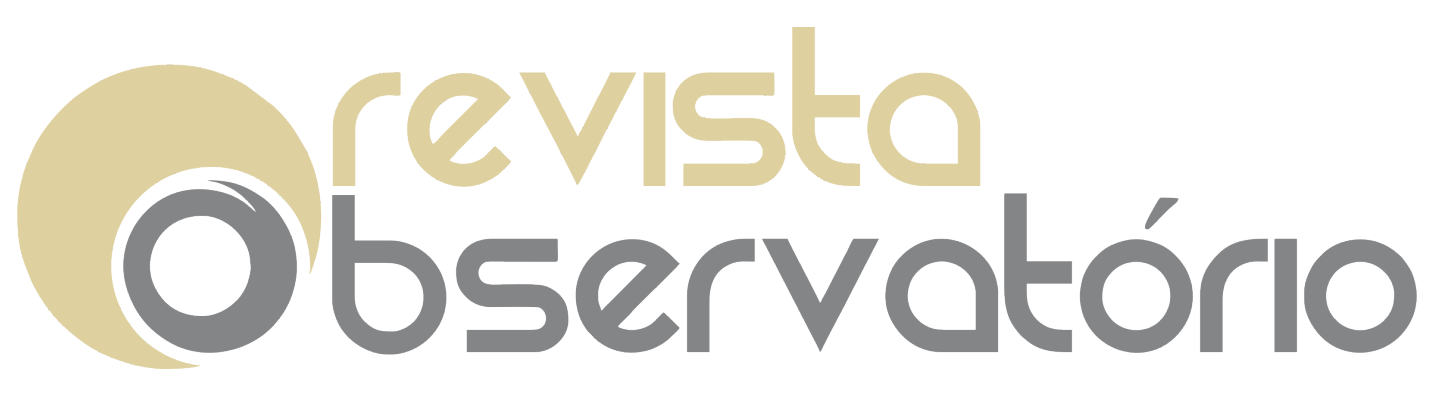

ISSN n² 2447-4266

Vol. 4, n. 4, Jul-Set. 2018

DOI: https://doi.org/10.20873/uft.2447-4266.2018v4n4p27

MACHADO, L. S.; COSTA, T. K. DE L.; MORAES, R. M. DE. MULTIDISCIPLINARIDADE E O DESENVOLVIMENTO DE SERIOUS GAMES E SIMULADORES PARA EDUCAÇÃO EM SAÚDE. Revista Observatório, v. 4, n. 4, p. 149-172, 29 jun. 2018.

MEDITSCH, Eduardo; Segala, Mariana. Trends in three 2003/4 Journalism academic meetings. Revista Brazilian Journalism Research, n.1, v.1, p.48-60, 2005.

MELLO, Gustavo; ZENDRON, Patrícia. Como a indústria brasileira de jogos digitais pode passar de fase. Jogos Digitais - BNDES Setorial, no. 42, 2015, p. 338-381.

MONTEIRO, Graça França. A Notícia Institucional. In: DUARTE, Jorge (org.). Assessoria de imprensa e relacionamento com a mídia: teoria e técnica. 2. ed. São Paulo: Atlas, 2006. p. 140-160.

MORAIS, C. DE S.; OSÓRIO, N. B. EDUCAÇÃO PARA O TRÂNSITO: metodologia e estratégias para atuação junto aos acadêmicos da universidade da maturidade na cidade de Araguaína/TO. Revista Observatório, v. 4, n. 4, p. 793-815, 29 jun. 2018.

NOGUEIRA, L. A NOTICIABILIDADE A PARTIR DO AUDIOVISUAL: da mídia tradicional à recirculação em redes sociais digitais. Revista Observatório, v. 4, n. 4, p. 445-467, 29 jun. 2018.

OLIVEIRA, A.; GADELHA, C.; COSTA, S. EXISTEM ELEITORES QUE COMERCIALIZAM O VOTO?. Revista Observatório, v. 4, n. 4, p. 816-832, 29 jun. 2018.

PEREIRA, F. H. AS NOTÍCIAS COMO PRÁTICA COLETIVA E CONVENCIONAL: a abordagem beckeriana aplicada aos estudos do jornalismo. Revista Observatório, v. 4, n. 4, p. 389-419, 29 jun. 2018.

PEREIRA, Fábio Henrique; ADGHIRNI, Zélia Leal. $O$ jornalismo em tempo de mudanças estruturais. Intexto, Porto Alegre: UFRGS, v. 1. n. 4. p. 38-57, jan./jun. 2011. Disponivel em: http://seer.ufrgs.br/index.php/intexto/article/view/19208/12362. Acessado em: 30/03/2018.

PINTO, M. DA G. L. C. A ESCRITA: uma prática movida pela busca da melhor adequação da execução à intenção. Revista Observatório, v. 4, n. 4, p. 763-792, 29 jun. 2018.

SANTHIAGO, R.; LACERDA, G. C. B. DE. MEMÓRIAS E NARRATIVAS: a vocação comunitária do Centro de Estudos e Pesquisas em Reabilitação (CEPRE/FCM/Unicamp) por meio da história oral. Revista Observatório, v. 4, n. 4, p. 684-713, 29 jun. 2018.

SANTOS, J. S. DOS; OSÓRIO, N. B.; GÓES, E. H. S. TDICS E GAMES NO ENSINO MÉDIO INOVADOR: memórias de professores criativos. Revista Observatório, v. 4, n. 4, p. 500-549, 29 jun. 2018.

SEIXAS, L. VALORES NOTÍCIA: uma proposta de análise. Revista Observatório, v. 4, n. 4, p. 334-366, 29 jun. 2018.

SILVA SOUSA, K. C. A COMUNICAÇÃO ON LINE NO ENSINO SUPERIOR COMO RECURSO DIDÁTICO NA PESQUISA EM EDUCAÇÃO. Revista Observatório, v. 4, n. 4, p. 550-570, 29 jun. 2018. 


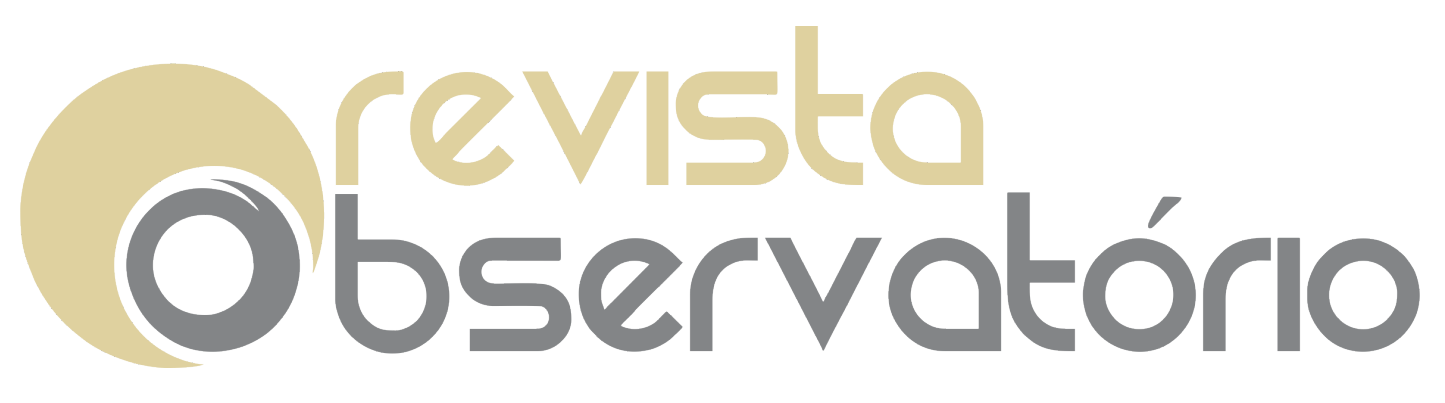

ISSN n² 2447-4266

Vol. 4, n. 4, Jul-Set. 2018

DOI: https://doi.org/10.20873/uft.2447-4266.2018v4n4p27

SILVA, G. A ENGRENAGEM DA NOTICIABILIDADE NO MEIO DO REDEMOINHO. Revista Observatório, v. 4, n. 4, p. 308-333, 29 jun. 2018.

SILVA, M. P. DA; JERONYMO, R. DE S. A CONSTRUÇÃO CULTURAL DE CRITÉRIOS NOTICIOSOS EM CONTEXTOS REGIONAIS: reflexões teórico-metodológicas a partir dos jornais de Corumbá (MS). Revista Observatório, v. 4, n. 4, p. 367-388, 29 jun. 2018. SILVEIRA, P. A ESCOLA E O MUNDO: pressupostos para a integração da atualidade na sala de aula. Revista Observatório, v. 4, n. 4, p. 638-659, 29 jun. 2018.

SOUSA, L.-C. S. C. S. PROPAGANDA ELEITORAL NAS NOTíCIAS: interfaces entre jornalismo e Programa Eleitoral Gratuito nas eleições para o governo do Maranhão. Revista Observatório, v. 4, n. 4, p. 714-737, 29 jun. 2018.

STRELOW, Aline. O estado da arte da pesquisa em jornalismo no Brasil: 2000 a 2010. Intexto, Porto Alegre, UFRGS, v.02, n.25, p. 67-90, dez. 2011.

TRAQUINA, Nelson. As noticias. In: TRAQUINA, Nelson (org). Jornalismo: questões, teorias e "estórias". Lisboa: Veja Ltda, 1993. P.167-176.

TRAQUINA, Nelson. Teorias do jornalismo: a tribo jornalística / uma comunidade Interpretativa internacional. Vol II, Florianópolis: Insular, 2005.

TRAQUINA, Nelson. Teorias do Jornalismo: porque as notícias são como são. Vol 1, Florianópolis: Insular/Pósjor UFSC, 2004.

VASCONCELLOS, M. S.; CARVALHO, F. G. DE; ARAÚJO, I. S. DE. "QUEM DEIXOU ISSO AQUI?!": Retórica procedimental e participação no desenvolvimento de um jogo em saúde. Revista Observatório, v. 4, n. 4, p. 75-112, 29 jun. 2018.

VELOSO, A. I.; RIBEIRO, T.; COSTA, L. QUANDO JOGO ATÉ ME ESQUEÇO DAS DORES: Jogos digitais como estratégia para a reabilitação física. Revista Observatório, v. 4, n. 4, p. 46-74, 29 jun. 2018.

VIZEU, A.; LEITE, F. DECIDINDO O QUE É NOTíCIA: 20 anos depois. Revista Observatório, v. 4, n. 4, p. 284-307, 29 jun. 2018.

Wolf, Mauro. Teorias da Comunicação. Lisboa: Editorial Presença, 2001. 